\title{
Staphylococcus aureus resistance to topical antimicrobials in atopic dermatitis*
}

\author{
Giancarlo Rezende Bessa ${ }^{1,2}$ \\ Daiane Corrêa Machado ${ }^{1}$ \\ Magda Blessmann Weber $^{1}$ \\ Pedro Alves D' Azevedo ${ }^{1}$
}

\author{
Vanessa Petry Quinto ${ }^{1}$ \\ Caroline Lipnharski ${ }^{1}$ \\ Renan Rangel Bonamigo ${ }^{1}$
}

DOI: http:/ /dx.doi.org/10.1590/abd1806-4841.20164860

\begin{abstract}
BACKGROUND: Topical antimicrobial drugs are indicated for limited superficial pyodermitis treatment, although they are largely used as self-prescribed medication for a variety of inflammatory dermatoses, including atopic dermatitis. Monitoring bacterial susceptibility to these drugs is difficult, given the paucity of laboratory standardization.

OвјестіvE: To evaluate the prevalence of Staphylococcus aureus topical antimicrobial drug resistance in atopic dermatitis patients. Methods: We conducted a cross-sectional study of children and adults diagnosed with atopic dermatitis and S. aureus colonization. We used miscellaneous literature reported breakpoints to define S. aureus resistance to mupirocin, fusidic acid, gentamicin, neomycin and bacitracin.

RESULTS: A total of 91 patients were included and 100 S. aureus isolates were analyzed. All strains were methicillin-susceptible S. aureus. We found a low prevalence of mupirocin and fusidic acid resistance $(1.1 \%$ and $5.9 \%$, respectively), but high levels of neomycin and bacitracin resistance $(42.6 \%$ and $100 \%$, respectively). Fusidic acid resistance was associated with more severe atopic dermatitis, demonstrated by higher EASI scores (median 17.8 vs 5.7, p=.009). Our results also corroborate the literature on the absence of cross-resistance between the aminoglycosides neomycin and gentamicin.

ConCLUSIONS: Our data, in a southern Brazilian sample of AD patients, revealed a low prevalence of mupirocin and fusidic acid resistance of $S$. aureus atopic eczema colonizer strains. However, for neomycin and bacitracin, which are commonly used topical antimicrobial drugs in Brazil, high levels of resistance were identified. Further restrictions on the use of these antimicrobials seem necessary to keep resistance as low as possible.
\end{abstract}

Keywords: Anti-infective agents, local; Dermatitis, atopic; Drug resistance, bacterial; Staphylococcus aureus

\section{INTRODUCTION}

Antimicrobial drugs applied topically offer several advantages over systemic administration, including avoidance of systemic toxicity and side effects, the decreased induction of bacterial resistance, high local concentration of antibacterial agents and low costs. ${ }^{1}$ Moreover, the broad use of this class of drugs is largely the result of self-prescription of over-the-counter preparations containing antibiotics, including ointments, eye-drops and otological solutions, uses that are supported by little or no scientific evidence. ${ }^{2}$
Staphylococcus aureus is the major causative agent of skin and soft tissue infections and treatment of S. aureus infections has become more difficult with time due to the emergence of multidrug-resistant strains. ${ }^{3}$ Atopic dermatitis (AD) is a chronic skin condition that has been strongly linked to the presence of S. aureus, while cutaneous infection constitutes an important mechanism of worsening disease. ${ }^{4}$ Thus, patients are frequently prescribed or self-prescribe antimicrobial medication, often topical preparations of antimicrobials associated with corticosteroids. Ambulatório de Dermatologia Sanitária do Rio Grande do Sul (ADS) - Porto Alegre (RS), Brazil.

Financial support: This work benefitted from resources from public institutions (federal and regional) that promote research (CNPq, CAPES, FAPERGS). Conflict of interest: None. 
However, there is growing concern over resistance to topical antimicrobials. ${ }^{5}$ Some of these drugs, such as fusidic acid, can also be used systemically in the treatment of methicillin-resistant $S$. aureus (MRSA) infections. ${ }^{6,7}$ Employing topical preparations in superficial infections and a variety of inflammatory dermatosis, including $\mathrm{AD}$, has been deemed responsible for the emergence of fusidic acid-resistant $S$. aureus (FRSA) strains. Some authors have called for its topical use to be restricted or even abolished. $8,9 \mathrm{Nev}$ ertheless, mupirocin can only be administered topically and its efficacy on S. aureus carriage eradication has disseminated its use for nasal decolonization. ${ }^{10}$ High-level mupirocin resistance, defined by minimum inhibitory concentration (MIC) $\geq 256 \mu \mathrm{g} / \mathrm{mL}$, has been increasingly reported and has emerged as a significant problem. ${ }^{11,12}$ It has been associated with multidrug-resistant MRSA isolates, and in a clinical setting, with decolonization failure. ${ }^{13-15}$ Finally, despite the wide use in several countries, information in the literature about topical neomycin and bacitracin antimicrobial activity remains limited.

Topical antimicrobial susceptibility testing is not routinely performed at laboratory centers. With the exception of mupirocin and fusidic acid, which have been discussed in many publications concerning bacterial resistance in recent years, data on other topical antimicrobial drugs are scarce. This raises concerns regarding the monitoring of these agents' continued efficacy.

The aims of this study were to: determine the prevalence of $S$. aureus topical antimicrobial resistance in $\mathrm{AD}$ patients according to standard procedures (for mupirocin and fusidic acid); verify neomycin and bacitracin activities against $S$. aureus isolates according to historical MIC breakpoints; analyze neomycin cross-resistance with gentamicin; and suggest ways to monitor the activity of commonly used topical antimicrobial drugs in a clinical setting.

\section{METHODS}

\section{Patients and isolates}

We conducted a cross-sectional study of children and adults diagnosed with $\mathrm{AD}$ who consecutively attended two outpatient dermatologic clinics in Porto Alegre, southern Brazil, over a oneyear period (December 2009 to December 2010). The diagnosis of $\mathrm{AD}$ was made by the treating dermatologist, based on standard criteria. ${ }^{16}$ Patients who had at least one dermatitis lesion at the time of their dermatologic visit were invited to participate. Following agreement from patients or children's parents, we collected patient demographics and information on their medical histories. The following data were recorded: self-reported use of topical and systemic antimicrobials over the previous year, skin infection episodes and hospitalization periods. Recurrent cutaneous infections were defined as involving three or more episodes by year. We also performed physical examinations to evaluate eczema severity according to the Eczema Area and Severity Index (EASI) score guidelines. ${ }^{17}$

For microbiological analyses, two sites from every patient were sampled with a sterile swab with transport medium in each case, namely: the anterior nose cavity and an eczema plaque without clinical signs of infection (pustules, serous crusts, purulent exudate). Swabs were sent to the microbiology laboratory and samples were inoculated onto Brain Heart Infusion agar with 5\% sheep blood and mannitol agar, and subsequently incubated at $35^{\circ} \mathrm{C}$ over- night. Each plate was examined for colonial morphology consistent with $S$. aureus. Isolates were identified according to standard procedures. ${ }^{11}$ Colonization was defined as positive culture for S. aureus on nasal cavities or cutaneous lesions and an absence of clinical signs of infection.

This study was approved by the Institutional Research Ethics Committee of the Universidade Federal de Ciências da Saúde de Porto Alegre. Prior to participation, informed consent was obtained from all patients and children's parents or legal guardians.

\section{Susceptibility Tests}

All strains were tested by disk diffusion assay on Mueller-Hinton agar with standardized procedures, according to the recommendations of the Clinical and Laboratory Standards Institute (CLSI). ${ }^{11}$ All isolates were tested beforehand for methicillin susceptibility, and all were categorized as methicillin-susceptible $S$. aureus (MSSA). The antibiotics disks used in this study were: gentamicin $(10 \mu \mathrm{g})$; neomycin $(30 \mu \mathrm{g})$; bacitracin $(10 \mu \mathrm{g})$; mupirocin $(5 \mu \mathrm{g})$; and fusidic acid $(10 \mu \mathrm{g})$. MIC was determined for bacitracin, mupirocin and fusidic acid using Etest ${ }^{\circledR}$ (BIOMERIEUX, Marcy-l'Etoile, France); and for neomycin using the broth microdilution method, according to the CLSI protocol. ${ }^{11}$

We used CLSI breakpoints to define gentamicin-resistant strains according to the disk diffusion assay. Recent CLSI publications provide no interpretative criteria for antibiotics of exclusive topical use, except for mupirocin. The technique for the mupirocin disk diffusion test from the CLSI constitutes merely a screening test that utilizes 256 $\mu \mathrm{g}$ disks to detect high-level mupirocin resistance in S. aureus strains. ${ }^{11}$ The other test interpretations were as follows. For mupirocin and fusidic acid MICs, breakpoints available from the European Committee on Antimicrobial Susceptibility Testing (EUCAST) publication were used. ${ }^{18}$ Bacitracin MIC criteria were available in the document from the Comité de l'Antibiogramme de la Société Française de Microbiologie (SFM) ${ }^{19}$ Neomycin MIC interpretative criteria were based on historical reports. ${ }^{20}$ For the mupirocin $5 \mu \mathrm{g}$ disk diffusion test, breakpoints outlined in publications from the British Society for Antimicrobial Chemotherapy (BSAC) Methods for Antimicrobial Susceptibility Testing were employed. ${ }^{21}$ There are two different inhibition zone sizes in EUCAST and BSAC publications for the Fusidic acid $10 \mu \mathrm{g}$ disk diffusion test. In accordance with both criteria, we sought to display fusidic acid resistance prevalence. No interpretative criteria were found for the neomycin $30 \mu \mathrm{g}$ and bacitracin $10 \mu \mathrm{g}$ disk diffusion test in the literature.

\section{Statistical Analysis}

Statistical analyses were conducted on SPSS software, version 17.0 (Chicago, IL, USA). Sampling was performed for a prospective study of MRSA colonization prevalence in AD patients, based on an expected frequency of $18.3 \% .^{22}$ Ninety-three patients were required to estimate population prevalence with significance set at $0.05 \%$ and power at $90 \%$. Continuous variables were summarized by mean or median values (and their respective variability measures) according to distribution symmetry, verified by Kolmogorov-Smirnov test. $\mathrm{MIC}_{50}$ and $\mathrm{MIC}_{90}$ were defined as the minimum inhibitory concentrations, encompassing 50 and $90 \%$ of isolates tested, respectively. 
For the statistical analysis, we included one isolate from each patient with positive cultures. For patients with two positive samples, we selected the isolate with the smallest inhibition zone diameter and the highest MIC for each antibiotic. For the comparative analysis, we applied the t-Student test for continuous variables with nearly normal distribution, and the Mann-Whitney test for continuous variables with asymmetric distribution, with significance set at $\mathrm{p}<0.05$. A two-sided Pearson's chi-squared analysis or Fisher's exact test, with $p<0.05$, was used to compare the categorical variables. The linearity relation between continuous variables was investigated via the Spearman's Correlation coefficient.

To evaluate the discrimination power of $30 \mu \mathrm{g}$ neomycin disk inhibition zone diameter according to neomycin MIC, all $S$. aureus isolates available were investigated and the area under the ROC (Receiver Operating Characteristic) curve was determined. We established the breakpoint of inhibition zone diameter to designate neomycin resistance according to neomycin MIC by calculating the sensitivity and specificity arithmetic mean and taking the point with the highest mean.

To evaluate aminoglycoside cross-resistance likelihood between gentamicin and neomycin, a logistic regression model was run, including gentamicin resistance defined by inhibition zone size, neomycin MIC and demographic variables, like sex, age and medical history. In all analyses, the significance level was set as $\mathrm{p}<0.05$.

\section{RESULTS}

A total of 91 patients were included in the study. Sixty-eight patients had at least one positive culture for S. aureus ( $48.4 \%$ of the swabs from cutaneous lesions and $61.5 \%$ from nasal cavities were positive). Topical antimicrobial resistance frequency is summarized in graph 1. All isolates were resistant to bacitracin. Concerning

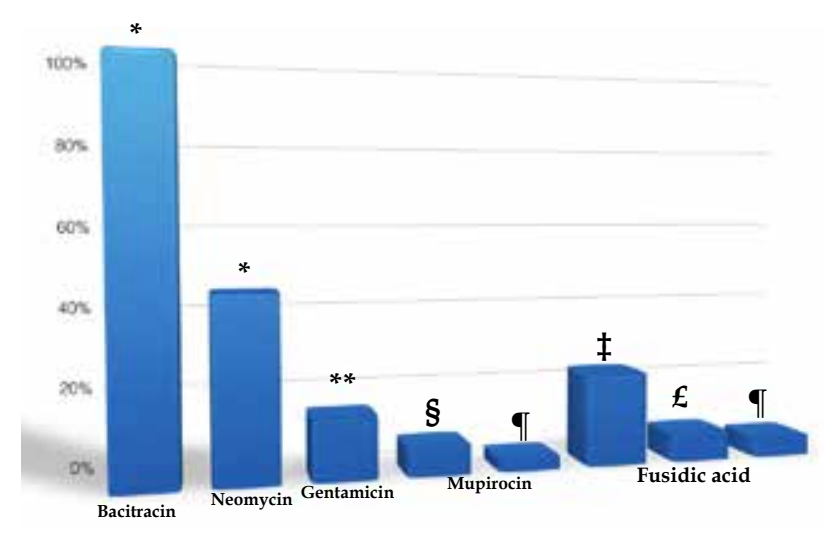

Resistance was defined by: * historical MIC breakpoints; ** CLSI standard $10 \mu \mathrm{g}$ disk diffusion assay; § BSAC breakpoint on $5 \mu \mathrm{g}$ disk diffusion assay; 9 EUCAST MIC breakpoints; $\ddagger$ BSAC breakpoint on $10 \mu \mathrm{g}$ disk diffusion assay; $£$ EUCAST breakpoint on $10 \mu \mathrm{g}$ disk diffusion assay.

GrapH 1: Relative frequencies of $S$. aureus isolates resistant to topical antimibrobials, cultured from the nose and cutaneous lesions of AD patients $(n=68)$ aminoglycosides, $42.6 \%$ and $14.7 \%$ were resistant to neomycin and gentamicin, respectively. Five isolates exhibited resistance to mupirocin upon the $5 \mu \mathrm{g}$ disk diffusion assay, but only one $(1.1 \%)$ was confirmed by MIC test. The existence of two different criteria led to significant discrepancies in interpretation of $10 \mu \mathrm{g}$ disk diffusion assay of fusidic acid. According to the BSAC ${ }^{21}$ breakpoint, $22.1 \%$ of isolates were resistant and this proportion dropped to $7.4 \%$ when the EUCAST ${ }^{18}$ breakpoint was used. MIC criteria (the same in both references) confirmed only four (5.9\%) isolates to be resistant to fusidic acid. The $\mathrm{MIC}_{50}$ and $\mathrm{MIC}_{90}$ values for the 68 isolates available for analysis are displayed in table 1 .

Demographic characteristics are shown in table 2, associated with colonization by resistant $S$. aureus. This analysis could not be performed for mupirocin due to the small number of resistant isolates. The only statistically significant association detected was between the EASI score and fusidic acid resistance (the greater the severity of AD, the higher the probability of colonization by FRSA, $p=0.009$ ).

Since testing neomycin susceptibility using a $30 \mu \mathrm{g}$ disk diffusion assay was not standardized, we performed an ROC curve analysis and set a value of $\geq 16 \mathrm{~mm}$ for the inhibition zone diameter to define susceptibility (according to the MIC reference) (Graph 2). Regarding aminoglycoside cross-resistance, our logistic regression model did not demonstrate an association between gentamicin and neomycin resistance ( $\mathrm{p}=0.896)$, adjusted by demographic and medical variables (Table 3 ).

\section{DISCUSSION}

This study evaluated the in vitro susceptibility of $S$. aureus to commonly used topical antimicrobials. Our data, from a southern Brazilian sample of AD patients, showed a low prevalence of mupirocin and fusidic acid resistance among $S$. aureus atopic eczema colonizer strains. All our strains were MSSA, but a previous study of MRSA carriers from an intensive care unit in Porto Alegre also demonstrated low levels of mupirocin resistance. ${ }^{23}$

MIC determination confirmed low levels of fusidic acid resistance in our sample. Clinical and laboratorial evidence support the hypothesis that the selection of naturally occurring mutant $S$. aureus is an important mechanism of fusidic acid resistance when exposed to the drug. ${ }^{24}$ Alsterholm et al. conducted a study on Sweden and found high proportions of FRSA in impetigo (as high as $75 \%)$ but a significantly lower prevalence $(6.1 \%)$ was detected in

TABLE 1: MIC50 and MIC90 of S. aureus isolates $(\mathrm{n}=68)$

\begin{tabular}{lcl}
\hline Antibiotic & MIC50 $(\mu \mathrm{g} / \mathrm{ml})$ & MIC90 $(\mu \mathrm{g} / \mathrm{ml})$ \\
\hline Neomycin & 1.5 & 17.6 \\
Bacitracin & 96 & $>256$ \\
Mupirocin & 0.19 & 0.38 \\
Fusidic acid & 0.38 & 0.75 \\
& & \\
\hline
\end{tabular}

MIC50 and MIC90 were defined as the minimum inhibitory concentrations encompassing 50 and $90 \%$ of isolates tested, respectively. 
TABLE 2: Sample demographic data according to S. aureus antimicrobial resistance

\begin{tabular}{|c|c|c|c|c|c|c|c|c|c|c|}
\hline \multirow[t]{2}{*}{ Demographic data } & \multicolumn{4}{|c|}{ All patients Gentamicin* } & \multicolumn{3}{|c|}{ Neomycin** } & \multicolumn{3}{|c|}{ Fusidic acid** } \\
\hline & $n=91$ & $\mathrm{R}(n=10)$ & $S(n=58)$ & $\mathbf{p}$ & $\mathrm{R}(n=29)$ & $S(n=39)$ & $\mathbf{p}$ & $\mathrm{R}(n=4)$ & $S(n=64)$ & $\mathrm{p}$ \\
\hline Male Sex - n(\%) & $48(52,7)$ & $5(50,0)$ & $33(56,9)$ & $0,740 \ddagger$ & $15(51,7)$ & $23(59,0)$ & 0,6259 & $2(50,0)$ & $36(56,3)$ & $1,000 \ddagger$ \\
\hline Age (years) & & & & $0,674 \S$ & & & $0,312 \S$ & & & $0,900 \S$ \\
\hline Range & $0,3-30$ & & & & & & & & & \\
\hline Mean \pm SD & $7,0 \pm 5,2$ & $6,6 \pm 2,2$ & $7,4 \pm 5,9$ & & $8,1 \pm 5,9$ & $6,7 \pm 5,3$ & & $7,0 \pm 3,8$ & $7,4 \pm 5,7$ & \\
\hline Median (IQR) & $\begin{array}{l}6,0 \\
(2,6-10,0)\end{array}$ & $\begin{array}{l}7,0 \\
(0,5-10,0)\end{array}$ & $\begin{array}{l}6,0 \\
(0,5-30,0)\end{array}$ & & $\begin{array}{l}7,0 \\
(0,5-30,0)\end{array}$ & $\begin{array}{l}6,0 \\
(0,6-26,0)\end{array}$ & & $\begin{array}{l}8,0 \\
(2,0-10,0)\end{array}$ & $\begin{array}{l}6,5 \\
(0,5-30,0)\end{array}$ & \\
\hline $\begin{array}{l}\text { Topical antibiotic } \\
\text { use - } \mathrm{n}(\%)\end{array}$ & $9,0(9,9)$ & $0(0,0)$ & $8(13,8)$ & $0,593 \ddagger$ & $3(10,3)$ & $5(12,8)$ & $1,000 \ddagger$ & $0(0,0)$ & $8(12,5)$ & $0,975 \ddagger$ \\
\hline $\begin{array}{l}\text { Previous skin } \\
\text { infection }-\mathrm{n}(\%)\end{array}$ & $30(33,0)$ & $4(40,0)$ & $20(34,5)$ & $0,733 \ddagger$ & $12(41,4)$ & $12(30,8)$ & 0,516 & $0(0,0)$ & $24(37,5)$ & $0,289 \ddagger$ \\
\hline $\begin{array}{l}\text { Recurrent } \\
\text { infections- } \mathrm{n}(\%)\end{array}$ & $24(26,4)$ & $3(30,0)$ & $16(27,6)$ & $1,000 \ddagger$ & $10(34,5)$ & $9(23,1)$ & 0,445 & $0(0,0)$ & $19(29,7)$ & $0,570 \ddagger$ \\
\hline $\begin{array}{l}\text { Systemic antibiotic } \\
\text { use }-\mathrm{n}(\%)\end{array}$ & $27(29,7)$ & $2(20,0)$ & $19(32,8)$ & $0,250 \ddagger$ & $9(31,0)$ & $12(30,8)$ & 1,000 & $2(50,0)$ & $19(29,7)$ & $0,658 \ddagger$ \\
\hline Hospitalization - n(\%) & $7(7,7)$ & $1(10,0)$ & $5(8,6)$ & $1,000 \ddagger$ & $2(6,9)$ & $4(10,3)$ & $1,000 \ddagger$ & $1(25,0)$ & $5(7,8)$ & $0,315 \ddagger$ \\
\hline $\begin{array}{l}\text { Disease duration } \\
\text { (years) } £ \\
\quad \text { range }\end{array}$ & $(0,1-30,0)$ & & & $0,896 \S$ & & & $0,121 \S$ & & & $0,444 \S$ \\
\hline $\begin{array}{l}\text { mean } \pm \mathrm{SD} \\
\text { median (IQR) }\end{array}$ & $\begin{array}{l}4,7 \pm 4,7 \\
3,0 \\
(1,5-6,3)\end{array}$ & $\begin{array}{l}5,2 \pm 2,7 \\
5,6 \\
(0,5-10,0)\end{array}$ & $\begin{array}{l}4,9 \pm 5,4 \\
3,0 \\
(0,3-30,0)\end{array}$ & & $\begin{array}{l}6,1 \pm 6,2 \\
5,0 \\
(0,3-30,0)\end{array}$ & $\begin{array}{l}4,1 \pm 3,8 \\
2,5 \\
(0,3-1,7)\end{array}$ & & $\begin{array}{l}6,8 \pm 4,0 \\
8,0 \\
(1,5-10,0)\end{array}$ & $\begin{array}{l}4,8 \pm 5,1 \\
4,0 \\
(0,3-30,0)\end{array}$ & \\
\hline $\begin{array}{l}\text { EASI score } £ \\
\text { range }\end{array}$ & $(0,4-40,5)$ & & & $0,965 \S$ & & & $0,437 \S$ & & & $0,009 \S$ \\
\hline mean $\pm S D$ & $7,8 \pm 8,1$ & $9,1 \pm 11,3$ & $9,0 \pm 8,3$ & & $9,9 \pm 8,1$ & $8,3 \pm 9,2$ & & $20,5 \pm 17,1$ & $8,3 \pm 7,6$ & \\
\hline median (IQR) & $\begin{array}{l}5,4 \\
(2,0-9,9)\end{array}$ & $\begin{array}{l}5,7 \\
(1,2-40,5)\end{array}$ & $\begin{array}{l}6,2 \\
(0,6-32,2)\end{array}$ & & $\begin{array}{l}7,3 \\
(0,6-32,2)\end{array}$ & $\begin{array}{l}4,9 \\
(0,6-40,5)\end{array}$ & & $\begin{array}{l}17,8 \\
(6,0-40,5)\end{array}$ & $\begin{array}{l}5,7 \\
(0,6-32,2)\end{array}$ & \\
\hline
\end{tabular}

§: Mann Whitney Test; ๆ: Pearson's Chi-square Test with continuity correction; †: Fisher's Exact Test; $£$ asymmetric variable; ${ }^{*}$ defined by disk diffusion technique; ** defined by MIC breakpoints. R: resistant; S: sensible; SD: standard deviation; IQR: interquartile range (the values between the 75th percentile and the 25th percentile).

TABLE 3: Cross-resistance between the aminoglycosides gentamicin and neomycin, adjusted by demographic variables (logistic regression model)

\begin{tabular}{|c|c|c|c|c|c|}
\hline \multirow{3}{*}{ Independent variables } & \multicolumn{4}{|c|}{ Gentamicin resistant } & \multirow{3}{*}{$\mathrm{p}$} \\
\hline & \multirow{2}{*}{$\begin{array}{c}\text { Coefficient } \\
\text { B }\end{array}$} & \multirow[t]{2}{*}{ SE } & \multicolumn{2}{|c|}{ Risk } & \\
\hline & & & OR & IC95\% & \\
\hline \multicolumn{6}{|l|}{ Factor } \\
\hline Neomycin MIC & 1,18 & 0,89 & 1,19 & $0,87-2,93$ & 0,258 \\
\hline \multicolumn{6}{|l|}{ Covariables } \\
\hline Male Sex & 0,77 & 0,82 & 2,15 & $0,43-10,81$ & 0,352 \\
\hline Female Sex & 0,31 & 0,12 & 0,87 & $0,11-2,11$ & 0,352 \\
\hline Age (years) & 0,16 & 0,17 & 0,12 & $0,84-1,66$ & 0,334 \\
\hline Topical antibiotics use & 19,5 & 14,62 & 0,99 & $0,21-3,03$ & 0,999 \\
\hline Previous skin Infection & $-0,15$ & 1,12 & 0,86 & $0,09-7,71$ & 0,894 \\
\hline Recurrent cutaneous infections & $-0,40$ & 1,29 & 0,67 & $0,053-8,427$ & 0,757 \\
\hline Systemic antibiotics use & 2,15 & 1,54 & 3,29 & $0,88-18,54$ & 0,214 \\
\hline Hospitalization & 0,88 & 1,37 & 2,41 & $0,16-35,31$ & 0,520 \\
\hline Disease duration (years) $£$ & $-0,121$ & 0,17 & 0,88 & $0,63-1,24$ & 0,483 \\
\hline EASI score (points) $£$ & $-0,01$ & 0,04 & 0,99 & $0,91-1,01$ & 0,828 \\
\hline
\end{tabular}

SE: standard error. OR: odds ratio. $€$ : model parameters: Pseudo-R2=0.237; -2 log Likelihood=46.750; Hosmer and Lemeshow ( $\mathrm{p}=0.896$ ). 


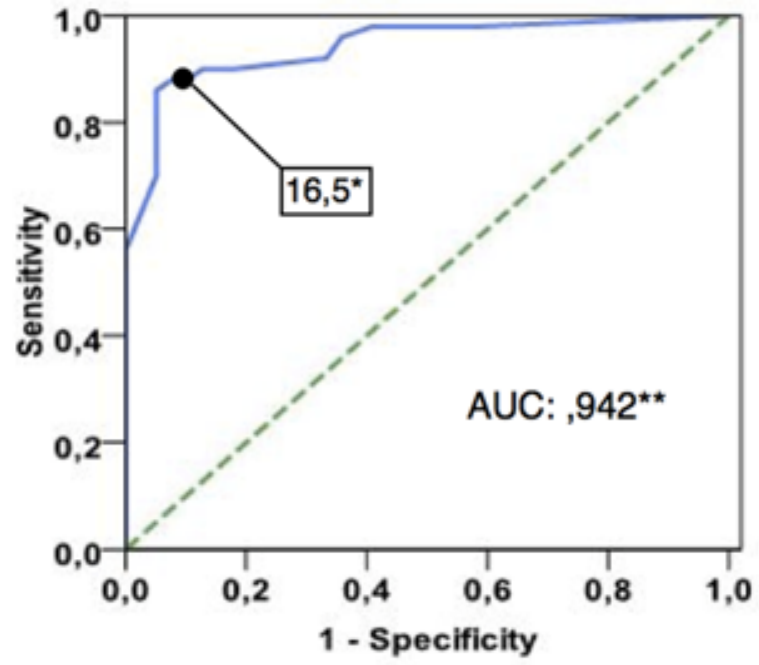

A value of $16.5 \mathrm{~mm}$ of inhibition zone diameter corresponded to the best breakpoint regarding sensitivity and specificity to define $S$. aureus susceptibility to neomycin by disk diffusion technique, using a $30 \mu \mathrm{g}$ neomycin disk. ** the Area Under Curve (AUC) was calculated as 0.942 (CI 95\% 0.895 to 0.989 . $\mathrm{p}<.0001)$

GrAPH 2: ROC curve analysis to define best inhibition zone size to define susceptibility to neomycin (according to MIC reference)

infected atopic dermatitis. ${ }^{25}$ Some authors hypothesized that the impetigo clone, described as being responsible for impetigo outbreaks in Europe, is not a frequent atopic dermatitis colonizer. ${ }^{26}$ In In Brazil, this low prevalence of resistance can also be explained by low use of topical mupirocin and fusidic acid. Products containing these drugs are relatively expensive and unavailable in the Brazilian public health system. In contrast, an ointment containing neomycin and bacitracin is a cheap and highly popular product, widely used as self-prescription medication for small wounds, insect bites and a variety of cutaneous infectious and inflammatory conditions, including AD. This can explain our high levels of neomycin and bacitracin resistance. All strains in our study were resistant to bacitracin according to a historical breakpoint and the $\mathrm{MIC}_{50}$ was considerably high $(96 \mu \mathrm{g} / \mathrm{ml})$. Our results also corroborate the literature about the absence of cross-resistance between neomycin and gentamicin, although an in vitro study has demonstrated that aminoglycoside resistance stability in $S$. aureus is closely linked to the resistance of strains to neomycin. ${ }^{27,28}$

For many years, the utility and importance of topical antimicrobials has been underestimated. With the emergence of multidrug resistant strains, like community acquired MRSA infections (CA-MRSA), any agent with an antistaphylococcal activity plays an important role in the limited armamentarium against these microorganisms, especially if the drug can also combat severe systemic infections, as fusidic acid does. ${ }^{12,29}$ In the literature, there is growing evidence of numerous clinical benefits of topical applied antibiotics (apart from impetigo treatment), notably S. aureus decolonization. In $\mathrm{AD}$ patients, despite a recent randomized placebo controlled study that suggested the efficacy of antiseptics and mupirocin in de- creasing the clinical severity of the disease, pooled evidence failed to demonstrate that antimicrobial administration (topical or systemic) aimed at reducing $S$. aureus colonization is clinically useful. ${ }^{30-34}$ However, the benefit of mupirocin use for S. aureus decolonization in other clinical circumstances has been demonstrated by many other studies. Intranasal mupirocin was associated with a significant reduction in surgical-site infections and proven to be a cost-effective approach in prosthetic orthopedic surgery. ${ }^{35,36}$ A systematic review showed a significant reduction in $S$. aureus nosocomial infections associated with intranasal mupirocin decolonization. ${ }^{37}$ Nonetheless, reports of $S$. aureus mupirocin resistance associated with eradication treatment have raised concerns over continued clinical efficacy. ${ }^{38}$ Clinical evidence demonstrates that judicious use to decolonize identified nasal carriers without $S$. aureus active infection should reduce resistance levels. ${ }^{39}$ As $S$. aureus decolonization clinical benefits become relevant and mupirocin becomes less active, studies of alternatives are necessary. Resistance to neomycin, bacitracin and polymyxin B was found to be rare in the USA, despite its long period of over-the-counter sales. ${ }^{27}$ A small study described successful MRSA decolonization using a triple compound (bacitracin, polymyxin B and gramicidin) in 9 out of 11 patients. ${ }^{40}$

The clinical significance of this in vitro study of topical antimicrobial resistance is uncertain and debate persists about appropriate breakpoints for susceptibility in laboratory testing. A topical product with a widely published breakpoint is mupirocin - susceptible at MIC $\leq 1 \mu \mathrm{g} / \mathrm{mL}$ and high-level resistance at MIC $\geq 256 \mu \mathrm{g} /$ $\mathrm{mL} .{ }^{18}$ Experts believe that only high-level mupirocin resistance may have clinical significance, and this breakpoint corresponds to an approximate 1:100 dilution of the marketed product. ${ }^{27}$ However, initial evidence shows that low-level mupirocin resistance combined with a genotypic chlorhexidine resistance significantly increases the failure of MRSA decolonization therapy. ${ }^{41}$ With the exception of mupirocin, breakpoints used for topical antibiotic susceptibility testing are not widely available. Neomycin and bacitracin historical breakpoints used in this study were selected to predict success in treating systemic infections at lower in vivo concentrations, not for treating superficial infections at higher concentrations. ${ }^{19,20}$ Bacitracin employment in systemic infections proved limited early due to its high nephrotoxicity, while neomycin was withdrawn following the development of less toxic aminoglycosides. ${ }^{1,20}$ This lack of standardization compromises topical antimicrobial resistance research and monitoring. In the absence of standardization, we considered neomycin historical MIC breakpoints and proposed an inhibition zone diameter of $16 \mathrm{~mm}$ to define resistance by using a $30 \mu \mathrm{g}$ neomycin disk to routinely monitor neomycin resistance in laboratory centers. Due to the $100 \%$ bacitracin resistance we found, it was not possible to establish a breakpoint for the bacitracin disk diffusion routine test.

\section{CONCLUSIONS}

Our data, from a southern Brazilian sample of AD patients, showed a low prevalence of mupirocin and fusidic acid resistance of $S$. aureus atopic eczema colonizer strains. However, for neomycin and bacitracin, commonly used topical antimicrobial drugs in Brazil, high levels of resistance were found. Although based on the an- 
tibiograms of local strains, our results raise an important discussion about topical antimicrobial resistance. Given the role of these drugs in decolonization and their potential use to prevent serious systemic infections due to prevalent endemic MRSA strains in any healthcare setting, further studies are necessary to determinate the efficacy and safety of antimicrobials other than mupirocin. The use of in vitro surveillance information and more restrictions regarding the use of these antimicrobials should lead to a decrease in resistant strains.

\section{REFERENCES}

1. Lio PA, Kaye ET. Topical antibacterial agents. Med Clin North Am. 2011;95:70321, vii.

2. Del Rosso JQ, Kim GK. Topical antibiotics: therapeutic value or ecologic mischief? Dermatol Ther. 2009;22:398-406.

3. Tognetti L, Martinelli C, Berti S, Hercogova J, Lotti T, Leoncini F, et al. Bacterial skin and soft tissue infections: review of the epidemiology, microbiology, aetiopathogenesis and treatment: a collaboration between dermatologists and infectivologists. J Eur Acad Dermatol Venereol. 2012;26:931-41.

4. Petry V, Bessa GR, Poziomczyck CS, Oliveira CF, Weber MB, Bonamigo RR, et al. Bacterial skin colonization and infections in patients with atopic dermatitis. An An Bras Dermatol. 2012;87:729-34.

5. Niebuhr M, Mai U, Kapp A, Werfel T. Antibiotic treatment of cutaneous infections with Staphylococcus aureus in patients with atopic dermatitis: current antimicrobial resistances and susceptibilities. Exp Dermatol. 2008;17:953-7.

6. Whitby M. Fusidic acid in the treatment of methicillin-resistant Staphylococcus aure-us. Int J Antimicrob Agents. 1999;12:S67-71.

7. Rennie RP. Susceptibility of Staphylococcus aureus to fusidic acid: Canadian data. J Cutan Med Surg. 2006;10:277-80.

8. Sule 0, Brown NM, Willocks LJ, Day J, Shankar S, Palmer CR, et al. Fusidic acidresistant Staphylococcus aureus (FRSA) carriage in patients with atopic eczema and pattern of prior topical fusidic acid use. Int J Antimicrob Agents. 2007;30:7882.

9. Howden BP, Grayson ML. Dumb and dumber--the potential waste of a useful antistaphylococcal agent: emerging fusidic acid resistance in Staphylococcus aureus. Clin Infect Dis. 2006;42:394-400.

10. Ammerlaan HS, Kluytmans JA, Wertheim HF, Nouwen JL, Bonten MJ. Eradication of methicillin-resistant Staphylococcus aureus carriage: a systematic review. Clin Infect Dis. 2009;48:922-30.

11. Clinical and Laboratory Standards Institute (CLSI). Performance standards for antimicrobial susceptibility testing. Twenty-First informational supplement. Document M100-S21. Wayne, PA: CLSI; 2011.

12. Elston DM. Topical antibiotics in dermatology: emerging patterns of resistance. Dermatol Clin. 2009;27:25-31.

13. McDanel JS, Murphy CR, Diekema DJ, Quan V, Kim DS, Peterson EM, et al. Chlorhexidine and mupirocin susceptibilities of methicillin-resistant staphylococcus aureus from colonized nursing home residents. Antimicrob Agents Che-mother. 2013;57:552-8.

14. Patel JB, Gorwitz RJ, Jernigan JA. Mupirocin resistance. Clin Infect Dis. 2009;49:935-41.

15. Fritz SA, Hogan PG, Camins BC, Ainsworth AJ, Patrick C, Martin MS, et al. Mupirocin and chlorhexidine resistance in Staphylococcus aureus in patients with community-onset skin and soft tissue infections. Antimicrob Agents Chemother. 2013;57:559-68.

16. Williams HC, Burney PG, Hay RJ, Archer CB, Shipley MJ, Hunter JJ, et al. The U.K. Working Party's Diagnostic Criteria for Atopic Dermatitis. I. Derivation of a minimum set of discriminators for atopic dermatitis. Br J Dermatol. 1994;131:383-96.

17. Hanifin JM, Thurston M, Omoto M, Cherill R, Tofte SJ, Graeber M. The eczema area and severity index (EASI): assessment of reliability in atopic dermatitis. Exp Der-matol. 2001;10:11-8.
18. Eucast.org [Internet]. European Committee on Antimicrobial Susceptibility Testing (EUCAST). Breakpoint tables for interpretation of MICs and zone diameters [cited 2016 Dec 26]. Available form: http://www.eucast.org

19. Members of the SFM Antibiogram Committee. Comité de l'Antibiogramme de la Société Française de Microbiologie report 2003. Int J Antimicrob Agents. 2003;21:364-91.

20. Waisbren BA. Neomycin. Practitioner. 1956;176:39-46.

21. Bsac.org.uk [Internet]. British Society for Antimicrobial Chemotherapy (BSAC). Methods for Antimicrobial Susceptibility Testing. Version 13 [cited 2014 Dec 26]. Available from: http://www.bsac.org.uk

22. Chung HJ, Jeon HS, Sung H, Kim MN, Hong SJ. Epidemiological characteristics of methicillin-resistant Staphylococcus aureus isolates from children with eczematous atopic dermatitis lesions. J Clin Microbiol. 2008;46:991-5.

23. Caierão J, Berquó L, Dias C, d'Azevedo PA. Decrease in the incidence of mupirocin resistance among methicillin-resistant Staphylococcus aureus in carriers from an intensive care unit. Am J Infect Control. 2006;34:6-9.

24. Turnidge $\mathrm{J}$, Collignon P. Resistance to fusidic acid. Int $\mathrm{J}$ Antimicrob Agents. 1999;12:S35-44.

25. Alsterholm M, Flytström I, Bergbrant IM, Faergemann J. Fusidic acid-resistant Staphylococcus aureus in impetigo contagiosa and secondarily infected atopic dermatitis. Acta Derm Venereol. 2010;90:52-7.

26. Lomholt HB. Fusidic acid resistant Staphylococcus aureus and skin disease. Acta Derm Venereol. 2010;90:4.

27. Jones RN, Li Q, Kohut B, Biedenbach DJ, Bell J, Turnidge JD. Contemporary anti-microbial activity of triple antibiotic ointment: a multiphased study of recent clinical isolates in the United States and Australia. Diagn Microbiol Infect Dis. 2006;54:63-71.

28. Dixson S, Brumfitt W, Hamilton-Miller JM. Stability of aminoglycoside resistance in vitro in gentamicin-resistant Staphylococcus aureus. J Hyg (Lond). 1984;93:43-9.

29. Gelatti LC, Bonamigo RR, Becker AP, D Azevedo PA. Methicillin-resistant Staphylococcus aureus: emerging community dissemination. An Bras Dermatol. 2009;84:501-6.

30. Huang JT, Abrams M, Tlougan B, Rademaker A, Paller AS. Treatment of Staphylococcus aureus colonization in atopic dermatitis decreases disease severity. Pediat-rics. 2009;123:e808-14.

31. Schuttelaar ML, Coenraads PJ. A randomized, double-blind study to assess the efficacy of addition of tetracycline to triamcinolone acetonide in the treatment of moderate to severe atopic dermatitis. J Eur Acad Dermatol Venereol. 2008;22:1076-82.

32. Hung SH, Lin YT, Chu CY, Lee CC, Liang TC, Yang YH, et al. Staphylococcus colonization in atopic dermatitis treated with fluticasone or tacrolimus with or without antibiotics. Ann Allergy Asthma Immunol. 2007;98:51-6.

33. Gong JQ, Lin L, Lin T, Hao F, Zeng FQ, Bi ZG, et al. Skin colonization by Staphylococcus aureus in patients with eczema and atopic dermatitis and relevant combined topical therapy: a double-blind multicentre randomized controlled trial. Br J Derma-tol. 2006;155:680-7.

34. Bath-Hextall FJ, Birnie AJ, Ravenscroft JC, Williams HC. Interventions to reduce Staphylococcus aureus in the management of atopic eczema: an updated Cochrane review. Br J Dermatol. 2010;163:12-26. 
35. Bode LG, Kluytmans JA, Wertheim HF, Bogaers D, Vandenbroucke-Grauls CM, Roosendaal $R$, et al. Preventing surgical-site infections in nasal carriers of Staphylococcus aureus. N Engl J Med. 2010;362:9-17.

36. Courville XF, Tomek IM, Kirkland KB, Birhle M, Kantor SR, Finlayson SR. Costeffectiveness of preoperative nasal mupirocin treatment in preventing surgica site infection in patients undergoing total hip and knee arthroplasty: a costeffectiveness anal-ysis. Infect Control Hosp Epidemiol. 2012;33:152-9.

37. van Rijen M, Bonten M, Wenzel R, Kluytmans J. Mupirocin ointment for preventing Staphylococcus aureus infections in nasal carriers. Cochrane Database Syst Rev. 2008:CD006216.

38. Kirk KF. Development of mupirocin resistance during eradication treatment of methicillin resistant Staphylococcus aureus carriage. Ugeskr Laeger. 2012;174:1310-1.

39. Vivoni AM, Santos KR, de-Oliveira MP, Giambiagi-deMarval M, Ferreira AL, Riley LW, et al. Mupirocin for controlling methicillin-resistant Staphylococcus aureus: lessons from a decade of use at a university hospital. Infect Control Hosp Epidemiol. 2005;26:662-7.

40. Fung S, O'Grady S, Kennedy C, Dedier H, Campbell I, Conly J. The utility of polysporin ointment in the eradication of methicillin-resistant Staphylococcus aureus colonization: a pilot study. Infect Control Hosp Epidemiol. 2000;21:653-5.

41. Lee AS, Macedo-Vinas M, François P, Renzi G, Schrenzel J, Vernaz N, et al. Impact of combined low-level mupirocin and genotypic chlorhexidine resistance on persistent methicillin-resistant Staphylococcus aureus carriage afte decolonization therapy: a case-control study. Clin Infect Dis. 2011;52:1422-30.
MAILING ADDRESS:

Giancarlo Rezende Bessa

Ambulatório do Serviço de Dermatologia da UFCSPA

Rua Capitão Montanha ,27

Centro

90010-040 Porto Alegre, RS.

E-mail:gianmed@yahoo.com

How to cite this article: Bessa GR, Quinto VP, Machado DC, Lipnharski C, Weber MB, Bonamigo RR, d'Azevedo PA. Staphylococcus aureus resistance to topical antimicrobials in atopic dermatitis An Bras Dermatol. 2016;91(5):604-10. 